\title{
Microbiology Test
}

National Cancer Institute

\section{Source}

National Cancer Institute. Microbiology Test. NCI Thesaurus. Code C49188.

A laboratory procedure to detect microorganisms in a sample. 